\title{
Research on University-enterprise Cooperation Mode in Colleges and Universities Based on Win-win Culture Perspective
}

\author{
Jiang Aihua and Long Jun \\ College of Electrical Engineering, Guangxi University, China \\ jiangaihua889@126.com
}

Keywords: Win-win culture, University-enterprise cooperatione, Model.

\begin{abstract}
Enterprises show unprecedented diversity characteristics aiming at demand for talents, and traditional education and teaching mode in colleges and universities can not meet current market development trend easily at some level under the background of current rapid development of economy. Therefore, university-enterprise cooperation arises naturally under such a background, which not only can effectively realize resource sharing, advantage complementariness s and mutual benefit between universities and enterprises, but also can assist students to obtain more broad space for development greatly. In the research of the paper, the author adopts electric major as an example and analyzes novel mode of university-enterprise cooperation from the perspective of win-win culture. It is expected that reference value can be exerted to certain extent.
\end{abstract}

\section{Introduction}

University-enterprise cooperation always belongs to an important way in the process of establishing electric major in colleges and universities. It is important environment to improve student practice ability and employment competitiveness. Currently, although more and more colleges and universities can realize the importance of university-enterprise cooperation, most cooperation activities become formalistic, rational training plan can not be formulated according to demand of society or enterprises. Students can not actually combine theory and practice.

\section{Talent demand for electrical engineering major}

Electrical engineering is a core technology in modern science and technology field, and it is also an indispensable key discipline in current high-tech field. Electrical engineering related technique supports the major from the perspective of the whole power generation field. Promotion and application of the technology will produce important influence on the whole power system. Currently, new process, new equipment and new technology have been widely used when large and medium-sized enterprises gradually enter a new stage of development. A large number of advanced production and processing equipment are adopted, and the demand of power plant for technical talents in the electrical engineering major also shows year-by-year increase trend.

\section{Analysis on situation survey of electric major university-enterprise cooperation in colleges and universities}

\section{Basic situation of survey}

The author adopts two methods of interview survey and questionnaire survey in order to accurately and timely understand current situation of electric major university-enterprise cooperation in colleges and universities. Two universities or colleges and their cooperation enterprises thereof in our province are selected successively for survey.

The author released a total of 200 questionnaires during the survey process, and 185 questionnaires were collected back with recovery rate of 93\%, including 162 effective questionnaires, a total of 61 students at school majoring in electricity in effective questionnaires accounting for 38\%, 32 teachers accounting for 20\%, 31 management staff in cooperative enterprises accounting for 19\%, 
and 38 grass-roots staff accounting for 23\% (as shown in figure 1).

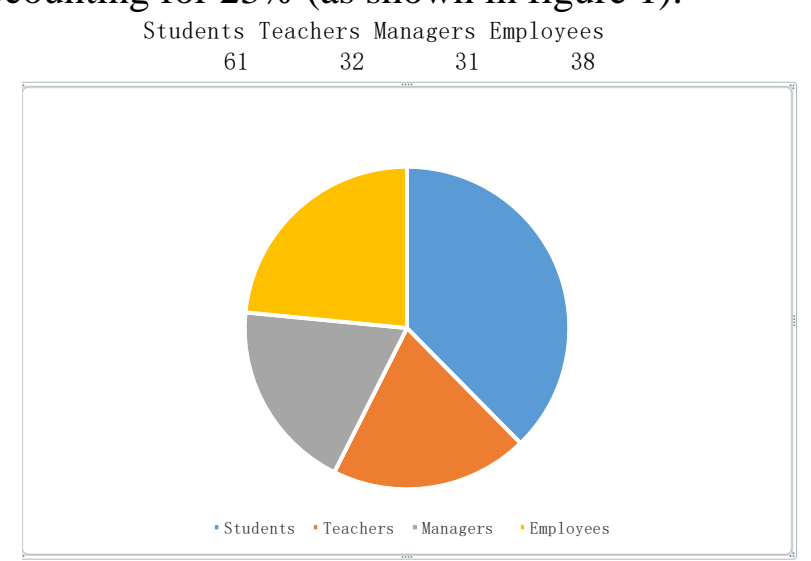

Figure 1. Occupation (post) distribution condition of respondents

\section{Analysis on survey results}

Insufficient university-enterprise cooperation depth in electrical major. Existing survey results show that although college administrators can pay full attention to the important significance of university-enterprise cooperation currently and cooperation can be practiced, about $80 \%$ schools can actually organize students for practicing in related companies, such as power plant and similar companies corresponding to the major. However, other cooperation modes are rare. In addition, lectures given by related personnel from foreign enterprises in colleges and universities account for about $20 \%$. Practice or part-time work of students at enterprises during summer and winter holidays account for $18 \%$. University-enterprise cooperation in other forms account for about $17 \%$ (as shown in Figure 2).

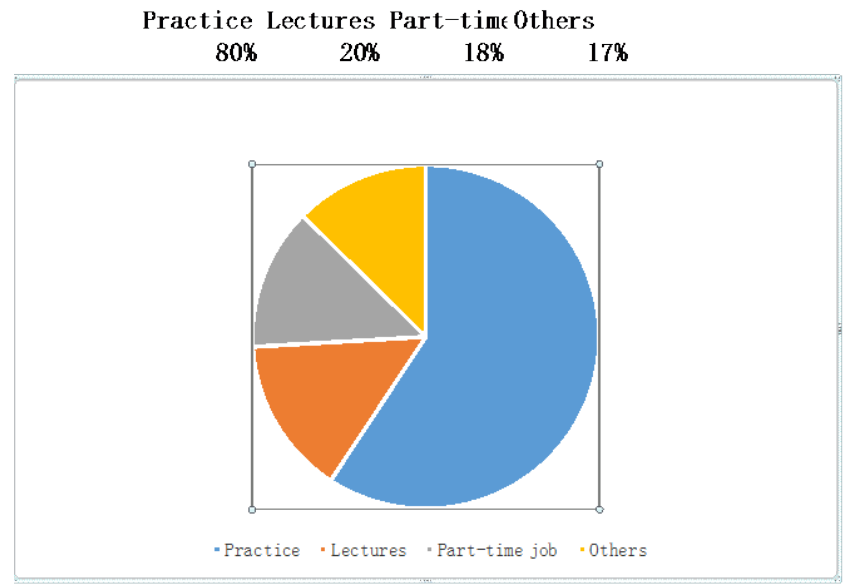

Figure 2. Main contents of current university-enterprise cooperation

It is visible that current university-enterprise cooperation depth is insufficient. Colleges and universities still treat main contents of university-enterprise cooperation at traditional practice level. Enterprise also simply obtains cheap labor from the schools. It is difficult to fit sustainable cooperation objectives between universities or colleges and enterprises. However, many contents in discipline should be practice aiming at electric major. For example, 'Electric Part of Power Plant' is an important technical professional course for electrical engineering major, which involves related contents of main electrical wiring, electrical appliance equipment and power distribution equipment on one hand, contains measurement, monitoring, protection and other aspects on the other hand. Course contents are relatively large without more obvious coherence (as shown in Figure 3). Students can not completely comprehend the contents in learning process. If university-enterprise cooperation can be effectively implemented, students' skills will be inevitably promoted. However, existing university-enterprise cooperation form has greater limitations, and therefore many students can not comprehend the learned contents, who can not fully understand such knowledge. 


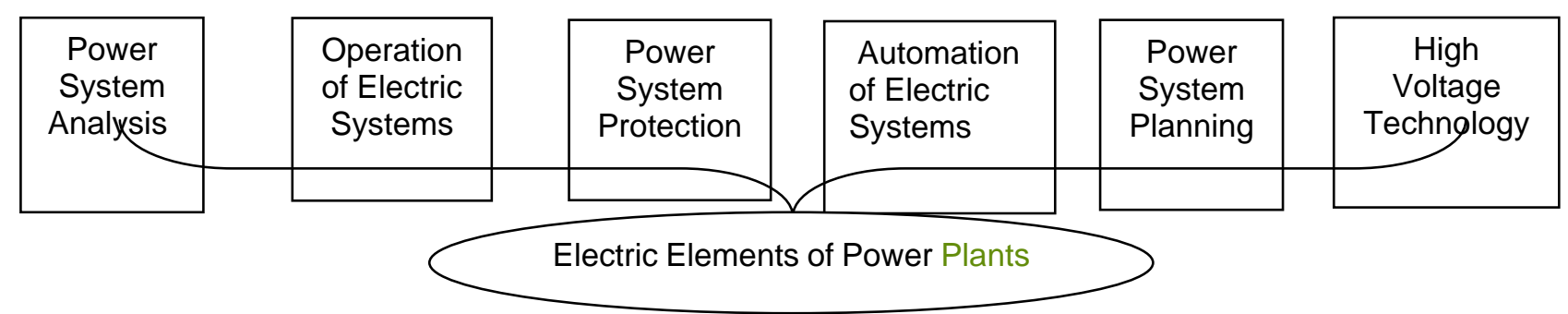

Figure 3. Related contents of electric part in power plant

Backward education and teaching contents. Internal managers of the power plant in the survey reflect that graduates cultivated by colleges and universities can not fit actual demand of own positions in both professional skills and comprehensive quality. Such conditions are produced mainly because current colleges and universities can not fully consider actual demand of employers during setup of courses, and there are many deficiencies during student cultivation. Effective and effective talent supply-demand information mechanism is not established between enterprises and universities or colleges from the perspective of external causes. Support function of related supporting facilities is insufficient. Economic benefits also should be considered firstly during cooperation between enterprises and schools, and own responsibilities in talent cultivation work should be correctly treated.

Dissatisfaction of Subjective demand of students. We comprehend that 'Electric Part of Power Plant' is an important course of electric major in the previous context from the perspective of combining theory and practice. It is also one of professional courses early contacted by students. Since students are lack of certain transition before contact with the course, students are lack of rational understanding on contents thereof inevitably. Though students can work in power plant in university-enterprise cooperation, work contents are most fundamental, which do not have direct content with own learned courses, and students can not combine book knowledge, actual electrical equipment and entire power system easily for exploration.

Secondly, university-enterprise cooperation can not effectively drive employment of graduates from the perspective of employment, or rare students can be recruited actually after practice in cooperation unit. University-enterprise cooperation has one important objective of realizing student output. However, such cooperation can not exert certain role in the aspect of student employment from current situation.

Difficult conversion of subject research results. University-enterprise cooperation not only provides development space for students, also provides materials and resources for the research of teachers. Generally speaking, subject research results jointly created during cooperation between students and enterprises can be converted into realistic productivity after being recognized by enterprises. Currently, many universities and colleges are still based on spontaneity of school teachers during topic research. However, teachers in electric engineering colleges do not have enough time and spirit to work in enterprises, therefore theory can not be tightly combined with practice during corresponding subject research. Many researches are only implemented at theoretical level without stronger practical feature, and corresponding economic benefits can not be brought to enterprises. However, each link of operation has stronger technical performance aiming at enterprises, such as power plant, etc. Any cracks will seriously affect the social production and living. Therefore, research results with high theoretical feature and low practicability can only be shelved, and enterprises are always lack of participation enthusiasm in research under university-enterprise cooperation.

\section{University-enterprise cooperation mode conception based on win-win cultural perspective and implementation strategies}

\section{'Win-win' mode conception}

Cooperation between schools and enterprises belongs to a two-way interactive behavior. Mutual benefit and win-win results can be realized after schools and enterprises actively participate in the 
process. Related course of 'Electric Part of Power Plant' is adopted as an example. After students study at the stage, students should participate in relevant practice, and power plant is the most relevant party in the course. However, power plants are rare in one city, and power plant has higher technology contents, it is generally difficult for universities and colleges to establish cooperation with power plants. Therefore, universities and colleges should consider from the perspective enterprise, enterprises can be assisted for expanding profit during satisfaction of enterprise benefits, and colleges can actively and positively participate in university-enterprise cooperation. It can be concluded that it is a starting point to construct win-win mode between enterprises and universities or colleges.

\section{Implementation strategy}

Scientific and effective university-enterprise cooperation 'win-win' mode conception. Firstly, important status and value of students in university-enterprise cooperation should be respected, and contents of students to participate in enterprise training should be tightly combined with enterprise equipment improvement. In particular, universities and colleges can made use of school fund to purchase production equipment required in cooperation enterprise. The production equipment can be applied to school practice teaching and enterprise production operation activities. It is worth mentioning that ownership of production equipment belongs to vocational colleges under such circumstance. When enterprises provides free services for student practice in cooperation colleges and universities, talent training fund should be withdrawn and returned to schools according to corresponding proportion. School fund and equipment can be flexibly mobilized on one hand, thereby exerting the maximum benefits, students can be assisted to timely contact with advanced production technology, thereby creating economic benefits for enterprises under such as cooperation mode.

Similarity combination and establishment of training platform according to enterprise demand. There are many categories in electrical engineering and automation professional foundation courses thereof (as shown in Figure 4). Some courses are completely independent. Contents contained in each course are not completely linked. For example, 'Electric Part of Power Plant' has huge and complicated contents, which can not be comprehended easily. Training and practice set in universities and colleges are implemented around courses. If cooperation enterprise should be searched for each item in each course, university-enterprise cooperation difficulty must be increased. Therefore, the author believes that enterprise demand should be considered, and training platform should be rationally established. Power plant category includes traditional coal-fired power plants, small hydropower station, solar power plant, wind power plant, garbage power plant, geothermal power plant, solar power plant, etc. Colleges and universities can distribute students majoring in new energy and a part of students majoring in electricity to power plants related to solar energy, wind energy and other new energy. Therefore, students majoring in electricity can mutually cooperate with students majoring in new energy for joint progress. Meanwhile, training resources also can be saved. In addition, several courses of 'Electric Part of Power Plant', 'Power Supply Technology', 'Failure Analysis of Power System', etc. can be concluded in the same lab. A training block platform can be jointly formed, which is beneficial for training students' ability in the aspects of power plant working procedures, electricity operation and maintenance.

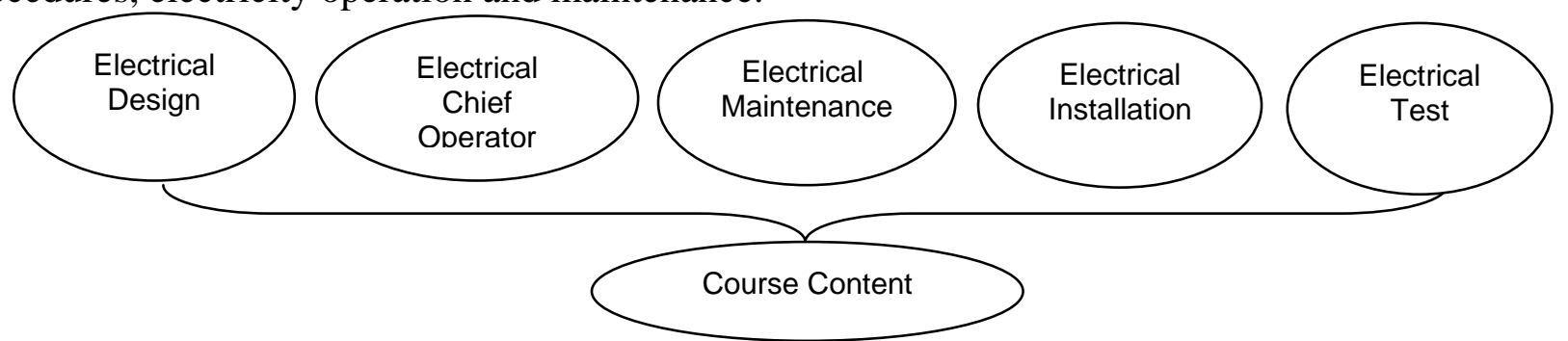

Figure 4. Course contents of electric engineering major

Colleges and universities should vigorously strengthen connotation construction and effectively improve own strength. Connotation construction should be strengthened mainly for maximally improving comprehensive quality and ability of students, which can exert own value after 
students enter the enterprises. Therefore, cooperation power between enterprises and universities or colleges can be further absorbed, and university-enterprise cooperation can be implemented on benign cycle. In fact, talent advantage and brand advance of universities or colleges should be mainly focused for participating in university-enterprise cooperation aiming at enterprises. After colleges or universities reach enterprise requirements in the two aspects, mutual benefits and win-win situation of university-enterprise cooperation can be realized.

Firstly, colleges or universities should strengthen construction of teacher team. Teachers of electric major not only should have relatively rich professional theory knowledge, but also should achieve solid professional practice experience, and teachers should have certain tracking and comprehension on enterprise operation and management mode. They can be quite capable in education and teaching activities, thereby scientifically leading students and inspiring students.

Secondly, colleges or universities can be guided by talent demand. Therefore, education and teaching modes can be reformed. Theory is always over-emphasized, and practice is ignored in traditional teaching activities. Students cultivated under such education form can not fit enterprise development need easily. Therefore, it is necessary for universities and colleges to actively communicate and coordinate with enterprises in the industry. Demand of the market for talents can be timely comprehended. Power plant should be adopted as an example. Since economy is developed rapidly in China, power generation by new energy shows new changes. If teaching contents are merely limited to thermal power plant, students cultivated in such a mode must have limitation in the aspect of employment, and schools can communicate with power plant in real time for comprehending current equipment status, operation condition and future development direction of power plants in China. Skill-based talents in line with enterprise demand can be cultivated in a targeted mode, therefore realizing resource sharing and win-win situation between enterprises and universities or colleges. Experts in the industry can be invited to schools under necessary condition, and they can be invited to participate in the whole process of teaching reform, and relationship between theory teaching and practice teaching can be handled from the forward-looking perspective.

Enterprises should have the courage to bear the social responsibility. Most power plants in China are state-owned. Their social responsibility and obligation are reckoned. Active participation in university-enterprise cooperation belongs to important obligation and responsibility of power plants. Responsibility awareness can be integrated into enterprise development strategy, thereby balancing relationship of stakeholders. University-enterprise cooperation not only can optimize enterprise operation and management mode, and improve enterprise technical strength, but also can bring good social reputation to enterprises. Therefore, enterprises can automatically update concepts and actively bear education responsibilities in university-enterprise cooperation.

\section{Conclusion}

Starting point and ending point of university-enterprise cooperation are always mutual benefit and win-win between enterprises and universities or colleges. Teacher forces should be optimized, and own strength and competitiveness can be improved, thereby providing scientific training platform for students as far as possible aiming at universities or colleges. It is necessary to transform consciousness, social responsibility and economic interests should be combined for actively bearing education responsibilities aiming at enterprises. Sustainable development of both parties can be driven only through active cooperation between universities or colleges and enterprises, and establishment of 'win-win' concept.

\section{References}

[1] Gao Hongmei. Research on university-enterprise cooperation mode based on the perspective of win-win culture. Hebei Normal University, 2012.

[2] Xu Zuohua. Research on university-enterprise cooperation mode in higher vocational colleges based on 'win-win' principle. Information of Science and Technology, 2015, 13 (8):241-241. 
[3] Zhang Jungui, Liu Junliang, Zhang Ming. Construction of novel professional practice base based on university-enterprise win-win cooperation. Laboratory Research and Exploration, 2013 (6).

[4] Yang Ming. Research on university-enterprise cooperation joint mode of high vocational colleges based on complementary win-win situation. Education and Profession, 2011 (36):39-40.

[5] Li Dongxia. Research on power mechanism of university-enterprise cooperation win-win in higher vocational colleges. Electronics Production, 2015 (2).

[6] Wang Huigang, Wei Yunping, Wu Na. Research on implementation of university-enterprise cooperation mode in local undergraduate colleges and universities. Wit, 2012 (11).

[7] Li Junjun. Analysis and research on university-enterprise cooperation mode and cooperation willing influence factors. Shanxi University of Finance and Economics, 2011.

[8] Song Lei, Yang Wen. Research on practice of university-enterprise cooperation mode. Electronic Test, 2015 (7):138-139.

[9] Gan Liya. Research on university-enterprise cooperation from the perspective of universities or colleges. Zhengzhou University, 2010.

[10] Tao Zi. Realization of win-win in university-enterprise cooperation. China Education Network, 2013 (12): 60-60. 